\title{
Determinants of cardiovascular and all-cause mortality in Northwest Russia: a 10- years follow-up study
}

Oleg Sidorenkov ${ }^{1 *}$, Odd Nilssen ${ }^{1}$, Andrej M Grjibovski ${ }^{1-3}$

\author{
${ }^{1}$ Institute of Community Medicine, University of Tromsø, Tromsø, Norway \\ ${ }^{2}$ Norwegian Institute of Public Health, Oslo, Norway \\ ${ }^{3}$ International School of Public Health, Northern State Medical University, Arkhangelsk, \\ Russia
}

Email addresses:

OS: Oleg.Sidorenkov@uit.no

ON: Odd.Nilssen@uit.no

AG: Andrei.Grjibovski@fhi.no

* Corresponding author: Institute of Community Medicine, University of Tromsø, postbox 9037, Tromsø, Norway. tel: +47 966 77157, fax +47 77644831

List of abbreviations and acronyms: CHD-Coronary heart Disease; GGT-gamma gultamyltransferrase, HBA1c-glycohemoglobin, ApoA1 and ApoB-apolipoproteins A1 and B, respectively, BAC-Blood Alcohol Concentration, AUDIT-Alcohol Use Disorders Identification Test, CAGE- CAGE questionnaire 


\section{Abstract}

PURPOSE: To study the factors associated with high cardiovascular (CVD) and allcause mortality in Russia.

METHODS: A prospective cohort study of 1966 men and 1738 women aged 18 years or more was performed in Arkhangelsk. The baseline examination was in 1999-2000. An average follow-up was 10.2 years. Information on life-style, marital, educational and psycho-social status was self-reported in a questionnaire. Data on risk factors were collected in a medical examination which included blood sampling.

RESULTS: To the October 2010 a total of 147 male and 95 women deaths occurred. In 59 male and 20 female deaths where diagnosis was made by a forensic pathologist, the autopsy data were studied to extract information on post-mortem Blood Alcohol Concentration (BAC). A positive BAC was found in 21(36\%) of male and 6(30\%) of female deaths. Women reporting a consumption of $80 \mathrm{~g}$ alcohol or more at least monthly and a consumption of 5 alcohol units or more on one drinking episode had higher risk of cardiovascular death than abstainers (RR was 5.06 (1.54-16.7) and 3.21 (1.07-9.58), respectively). ApoB/ApoA1-ratio was the strongest predictor of CVD and all-cause death in men (RR 7.62(3.15+18.4) and 4.39(2.22-8.68), respectively) and CVD death in women: RR 3.12 (1.08-8.98). Men with obesity and university education had 40\% lower risk of all-cause death. Low serum albumin was associated with high mortality in both genders.

CONCLUSIONS: Hazardous alcohol consumption is an independent risk factor of CVD mortality also in women. The mechanisms behind its damaging effect are yet not clear. Nutritional factors such as serum albumin are important. Further studies are needed. 
MeSH heading key words: Russia, mortality, cardiovascular death, alcohol intake, Blood Alcohol Concentration, apolipoproteins, serum albumin, gamma glutamyl tansferrase, C-reactive protein, Body Mass Index

Running title: Predictors of high mortality in Russia 


\section{Introduction}

Cardiovascular and all-cause mortality in Russia is among the highest in Europe. The age-standardized cardiovascular death rates are higher in all age groups of Russian men and women than the corresponding average estimates for the 27 countries of Western Europe (Eur-A). The difference at working ages is particularly high: a 9-fold in men and a 6-fold in women aged 30-44 years, and 7-fold in men and women aged 45-59 years(1) and explains most of the difference in life expectancy between Russia and other industrialized countries. The total number of deaths exceeded the number of births by almost 1 million in 2000 and by 850.000 in 2005(2)!

There is also a large difference in mortality between men and women in Russia resulting in gender imbalance with a male-to-female ratio of 0.87 (3) which is among the lowest in the world's. The ratio rapidly decreases with age and at the age over 60 years it wa below 0.5 in 2006 (4) while the corresponding ratio for Norway was 0.80 the same year (5). High premature mortality from cardiovascular diseases and external causes among Russian men is the main cause of the large gap in life expectancy between men and women (6). In 2003, life expectancy at birth was 58.6 years for men and 71.8 for women, since then it has increased to, respectively, 62.8 and 74.7 years in 2009(7), although it is still much lower than in Europe.

Contrary to high cardiovascular mortality, population-based studies from Russia have failed to reveal high levels of conventional risk factors, taken either individually 
$(8 ; 9)$ or combined as a risk score $(10-12)$. Instead, hazardous alcohol consumption was suggested as the main determinant of high cardiovascular(13) and all-cause mortality(14;15) among Russian men. Other risk factors such as low socio-economic status (16;17), unhealthy lifestyle (18) and psycho-social distress have also been studied (19). It was also suggested that cardiovascular mortality is artificially inflated due to misattribution of alcohol poisonings to cardiovascular deaths(6). However, it was not supported by other studies (13).

Only two longitudinal studies on factors associated with cardiovascular and allcause mortality had been performed in Russia. The first included only men aged 40-59 years and was performed during the 1980s in Moscow and St. Petersburg (17). The other study included men and women aged 25-64 years and collected data during the 1990s in Western Siberia. Taking into account vast distances, ethnical and cultural heterogeneity of Russia, there is still a need in such longitudinal studies in Russia.

The principal aim of this study is to assess the influence of both conventional and novel risk factors (apolipoproteins, C-reactive protein, GGT, serum albumin and alcohol intake) on cardiovascular and all-cause mortality by gender in a typical Northwestern Russian town.

\section{Methods}

This is a prospective cohort study conducted in Arkhangelsk, Northwest Russia. Altogether, 1966 men and 1738 women aged $\geq 18$ years who attended one outpatient 
clinic in 1999-2000 comprised the cohort. The response rate was 98.9\%. The participants underwent a medical examination, filled in a 6-page questionnaire and had blood tests drawn for laboratory analyses. Extensive details about recruitment and data collection are given elsewhere(11;20).

Marital status was dichotomized as single or married. The former group included also divorced, widowed and cohabiting. Education was divided into 3 categories: secondary school or lower, college (vocational school or incomplete university education) and university. Occasional and daily smokers were classified as smokers, while non-smokers and ex-smokers were coded as non-smokers. By leisure-time physical activity the participants were dichotomized into active, who reported walking or bicycling or yard working at least 4 hours per week, regular training or professional sport and inactive (low physical activity).

Alcohol consumption was described both as a frequency of consumption and volume of alcohol consumed on one drinking episode. The frequency of alcohol consumption was classified into 4 groups: abstainers, $\leq 1$ time a month, 2-4 times a month, $\geq 5$ times a month. The number of alcohol units (AU) on one occasion was categorized as abstainers, 1-4 AU and $\geq 5$ AU. One AU was equal to $13.8 \mathrm{~g}$ of pure alcohol or $40 \mathrm{ml}$ of vodka, or one $120 \mathrm{ml}$ glass of table wine. Frequency of 6 or more AU consumption (6 AU was equivalent to about $250 \mathrm{ml}$ of vodka) on one drinking session was presented as never (included abstainers), less than once a month and $\geq 1$ time a month. Furthermore, the Alcohol Use Disorder Identification Test (AUDIT) and the CAGE test, respectively, 
consisting of 10 (giving a maximum score of 40) and 4 items (a maximum score of four) were used to assess alcohol intake.

The examinees who answered "yes" to the question "Do you have periods of 2 weeks or more during which you feel sad, blue or depressed?” were classified as having depression. As having sleeping disorders were defined those who answered "yes" to the question "Do you have periods of 2 weeks or more during which you have problems with sleep?” Quality of life was self-evaluated according to a scale from one to ten (Cantril Ladder), where one represents the worst quality of life; as having low quality of life were considered those subjects who had scored less than 5 .

Weight and height were measured with subjects in light clothing and without shoes. A BMI of $<25,25-29.9$, and $\geq 30 \mathrm{~kg} / \mathrm{m}^{2}$ corresponded to normal weight, overweight and obesity, respectively. Diastolic blood pressure (DBP) was measured three times on the right arm in a sitting position. The average of the two last readings was used in the analyses.

Details on measuring total cholesterol (TC), high-density lipoprotein cholesterol (HDL-C) and triglycerides (TG) are described elsewhere (11), as well as for C-reactive protein (CRP), gamma-glutamyltransferase (GGT) and glycohemoglobin (HBA1c) (12). Serum albumin was measured colorimetrically by an automated method using bromcresol green as the indicator on Hitachii-917 analyzer. Apolipoproteins A1and B were assayed by an immunoturbidimetric method with polyclonal sheep anti-human apolipoprotein antibodies (Roche). Analytic coefficient of variation was $\leq 3 \%$ for all laboratory measurements except TC (5\%). 
The cohort was followed-up until 1 October 2010. The mean duration of followup was 10.2 years. The list of participants was annually checked against the regional mortality registry. The last check was performed in November 2010. Underlying cause of death coded according to the International Classification of Diseases, 10th Revision (ICD-10) was retrieved from death certificates. The study end-points were cardiovascular death (I00-99) and death from all causes. Moreover, in cases where diagnosis was made by forensic expert we applied to the Regional Centre of Forensic Expertise where all forensic autopsies in Arkhangelsk are performed. A testing on presence of alcohol and alcohol surrogates with measurement Blood Alcohol Concentration (BAC) is a standard procedure of the forensic autopsies in case of death due to cardiovascular diseases or external causes. The proportion of deceased subjected to forensic autopsy decreases with age. Data on presence of alcohol or alcohol surrogates were extracted from the autopsy records.

Differences between genders by the studied characteristics were studied by unpaired t-tests and Pearson's chi-squared tests for continuous and categorical variables, respectively. Gender-specific relative risks (RR) adjusted first by age (Model 1) and all studied variables (Model 2) for all-cause and cardiovascular death with 95\% confidence intervals (CI) were estimated using Cox regression.

The study was approved by the Regional Ethics Committee in Tromsø, Norway, and verbal informed consent was obtained from all participants.

\section{Results}


Baseline characteristics of the cohort by gender are presented in Table 1. Men smoked more and had more hazardous pattern of alcohol consumption. Women scored less than men on the AUDIT and CAGE tests. The proportion of single and subjects with university education was higher in women.

The means of TC and glycohemoglobin and prevalence of obesity (BM£30) were higher among women.

Altogether, 242 subjects (147 men and 95 women) died during a 10-year followup by October 2010 (Table 2). Deaths from cardiovascular diseases constituted the majority in men ( $n=77(52.4 \%)$ and women ( $n=52(54.7 \%)$. Among all cardiovascular deaths Coronary Heart Disease (CHD; ICD-10 codes I20-25) accounted for 69\% (53 deaths) in men and 48\% (25 deaths) in women. Deaths from myocardial infarction (ICD10: I21-23) constituted only 21\% (11 deaths) and 28\% (7 deaths), respectively, in men and women of all CHD-deaths. Fifteen men and women died from cerebral stroke, constituting, respectively, $19.5 \%$ and $28.8 \%$ of all cardiovascular deaths. The mean age of cardiovascular death was 63.4 years (SD 13.5) for men compared to 70.0 (12.2) for women.

Malignancies accounted for the next largest group of decedents. The most frequent cancer localizations in men were lung (9 deaths) and esophagus/stomach (8 deaths). The most frequent form in women was cancer coli (6 deaths). Mean age for men in this group was 58.5 (11.9) years, and for women 61.2 (12.3) years.

The group of “external causes” refers to accidents and suicides/homicides. Mento-women ratio in this group was 3.5:1. The majority of deaths occurred at the age of less than 50 years. All four deaths in subcategory including suicides and homicides in men 
were suicides, whereas two of three female deaths in this group were due to violence (homicide). The mean age of death was the lowest in the group of external causes for both genders when compared with other groups. It was 46.3 (13.2) and 30.0 (10.2) years, respectively, for men and women.

\section{Cardiovascular mortality}

Lower levels of serum albumin, HDL-cholesterol, higher CRP levels, LDL/HDLand ApoB/ApoA1-ratios, $\mathrm{DBP} \geq 90 \mathrm{mmHg}$ were associated with increased risk of cardiovascular death among men (Table 3). Self-reported consumption of 1-4 AU on one occasion and frequency of alcohol consumption of once a month or less were associated with almost double risk of death compared to abstainers among men.

The pattern of association for alcohol-related variables differed between genders. Women who reported consumption of $5 \mathrm{AU}$ or more at one drinking session and taking $80 \mathrm{~g}$ of alcohol once a month or more, had, respectively, 3 and 5 times the risk of cardiovascular death of abstainers. An average increase in one score on the scale of AUDIT increased risk of cardiovascular death by $26 \%$ ( $\mathrm{p} \leq 0.001$ ); the corresponding risk estimate for CAGE was higher (RR 2.46 per increase in one score, $p \leq 0.001$ ). An increase in ApoB/ApoA1-ratio by 1 was associated with a 3-fold increase in risk.

\section{All-cause mortality}

In men, university education was associated with $40 \%$ lower risk of all-cause death. High CRP levels, DBP $\geq 90$ mmHg, high LDL/HDL-and ApoB/ApoA1-ratio were associated with increased all-cause mortality in men (Table 4). A higher risk of death from all causes was found in men and women with low levels of albumin and HDL-C. 
Among women, age-adjusted all-cause mortality was higher in women with high levels of GGT.

One of the major findings was that the risk of all-cause death in obese men was lower than in normal-weight men.

\section{Forensic examinations}

Of 242 death certificates 42 (17.4\%) were filled-up by a hospital pathologist and 79 (32.6\%) by a forensic pathologist. More men than women were subjected to forensic autopsy (ratio 3:1). Positive BAC or presence of surrogates (3 cases) was found in 27 cases (Table 5). Of 7 alcohol-positive cases among men who died from external causes 6 were due to fatal intoxication with alcohol or its surrogates. In 3 cases $\mathrm{BAC} \geq 5.0 \%$ was found, in other 3 cases alcohol surrogates were revealed.

In the majority of alcohol-positive cardiovascular deaths BAC was less than $1 \%$ (11 deaths from CHD: I20-25). A BAC of 2.97\%o and 2.26\%o was recorded for two male deaths, respectively, from ruptured aortic aneurism (I71.1) and unspecified cardiomyopathy (I42.9). Of 4 BAC-positive deaths from “other diseases” two were alcohol-related; acute pancreatitis (K85) and alcoholic liver cirrhosis (K70.3). Other two were death from pneumonia (J18.1) and a case were cause wasn’t identified (R98).

\section{Discussion}

\section{Main findings}

This was the first cohort study from Russia where a significant dose-response association between hazardous alcohol consumption and the risk of cardiovascular death was found in women. A consumption of $80 \mathrm{~g}$ alcohol (250ml vodka) or more at least 
monthly was associated with a 5-fold increased risk of cardiovascular death compared to the reference group. Binge drinking (a consumption of $\geq 5$ AU on occasion) was associated with a 3-fold risk compared to abstainers. A positive answer on one item of the AUDIT and the CAGE questionnaires, in average, respectively, increased the risk of cardiovascular death by 1.26 and 2.45 times.

In men, university education and obesity $\left(\mathrm{BM} \geq 30 \mathrm{~kg} / \mathrm{m}^{2}\right)$ were associated with $40 \%$ lower risk of death from all causes. The presence of arterial hypertension was associated with a 1.75-fold risk of death from cardiovascular diseases and all causes in men. Low levels of serum albumin in both genders and the high LDL/HDL and ApoB/ApoA1 ratio in men strongly predicted the 10-year mortality from cardiovascular diseases and all causes. Low serum levels of HDL-C were associated with higher allcause (both genders) and cardiovascular mortality (in men).

\section{Limitations}

The study had several limitations. The first one was the young age and relatively small size of the cohort. Only 638 (32.5\%) men and 626 (36.0\%) women were 50 years or more at the beginning of follow-up which resulted in loss of statistical power. Loss to follow-up is another weakness. We used the regional person-sensitive mortality statistics based on official death certificates for death registration to identify the deceased, since no national personalized mortality registry available for research exists in Russia. Therefore, we were unable to trace the participants who moved from the Arkhangelsk region during the follow-up. Hence, those who died outside the region were not registered as the "case". Although, this problem is likely common for all longitudinal studies from Russia using the same source of mortality data $(16 ; 21 ; 22)$. If the rate of out-migration from the cohort 
was the same as ifrom the Arkhangelsk region (4;23), estimated annual loss to follow-up would be between 2\% in 1999, 1.2\% in 2005 and 2009, constituting, in average, around $15-17.5 \%$ loss during the 10 -year observation period. The probability of migration was higher among young people ( $\leq 30$ years), in the age-groups were cardiovascular mortality was the lowest. The third limitation was that unemployed and marginalized individuals such as alcohol abusers and homeless were underrepresented in the cohort. All three limitations weakened the observed associations and resulted in underestimation of RR.

\section{CVD-death and alcohol}

The few epidemiological studies of alcohol and cardiovascular and all-cause death were mainly performed in middle-aged men(13;17;22). The only longitudinal study which included women was undertaken in 1980s. It studied effects of conventional risk factors and disregarded exposure to alcohol(24). The only large study where effects of alcohol consumption on mortality were assessed in women had obvious methodological limitations: a case-control design, the crude measurement of exposure to alcohol (in bottles of vodka consumed per week), a high probability of recall bias (data were collected 8-9 years after death from a proxy-respondent), low response rate of $25 \%$ and a questionable selection of the reference group(15). This study found a significant dosedependent association of alcohol drinking with death from CHD and stroke. However, its results are not directly comparable with ours due to different measurement of alcohol consumption.

Why no significant effect of hazardous drinking was demonstrated among men in our study? The majority of male and only few female participants were active workers employed in wealthy sea-fishing industry with a relatively high salary. They were 
recruited during the obligatory medical check-up organized in the see-men out-patient clinic. Although very few men were not willing to participate, it is likely that many of them distrusted our reassurances that the collected data will be confidential and unavailable to the employer. To avoid possible conflict with employer some of them could underreport estimates of alcohol consumption. This hypothesis finds its explanation in the data; men reporting frequency of alcohol consumption once a month or less and a consumption of 1-4 AU on one occasion had almost 2-fold and 1.5-fold increased risk of cardiovascular death and all-cause death, respectively, compared to abstainers. Higher proportion of men than women (14.3\% vs. 6.3\%) had positive result of alcohol test at forensic autopsy.

\section{BMI and all-cause mortality in men}

Our finding that obesity (BMI $\geq 30)$ was inversely related to 10 -year all-cause mortality among Russian men was unexpected. Only one study from Russia investigated the risks of cardiovascular and all-cause death associated with BMI (25). It included only men and found no association with all-cause mortality. The same cohort study unexpectedly found an increased risk of death from CHD among Russian middle-aged men with lowest levels of TC and LDL-C(26). This association was present only among men having the lowest educational level. The authors have also reported a higher ageadjusted cardiovascular and all-cause mortality (Visit2) among men with higher levels of HDL-C. Men with the lowest levels of TC and LDL-C had also higher HDL-C, consumed more alcohol and had lower mean BMI(21). The authors suggested that other factors (among them educational status) might modify association between serum lipids and mortality. In our study BMI was unequally distributed across the strata of education 
and marital status in men. The lowest BMI was found among unmarried men and men with secondary professional education. In our study BMI was strongly associated with lipid status: the mean LDL/HDL- and ApoB/ApoA1-ratio significantly $(\mathrm{p}<0.03)$ increased across the BMI levels in both genders. Inclusion of ApoB/ApoA1- and, in less degree, LDL/HDL-ratio in the regression has strengthened the inverse association between BMI and mortality.

A strong positive association of ApoA1 concentration with frequency and volume of alcohol consumption has earlier been described in our study(27) and was in line with the results from studies on Western populations(28;29). It is possible that the ApoB/ApoA1-ratio being included into the regression might not only be a factor reflecting lipid status but also the factor revealing residual confounding effects of alcohol consumption underestimated by self-report. Hence, obesity and education are likely the markers of a social group having the life-style, which is inversely associated with the risk of all-cause death. The life-style characterized by higher ApoB/ApoA1-ratio and lower alcohol consumption.

\section{Serum lipids and mortality}

Of five variables describing lipid status: TC, HDL-C, TG, ApoB/ApoA1- and LDL/HDL-ratio only ApoB/ApoA1-ratio predicted cardiovascular death in both genders. Remarkably, the positive association of ApoB/ApoA1-ratio with cardiovascular and allcause mortality was considerably stronger among men, in whom the ratio was the strongest predictor of 10-year risk of death among all other factors included in the regression. The lipid-transporting apolipoproteins: ApoB, transporting proatherogenic VLDL and LDL particles, and ApoA1, transporting antiatherogenic HDL particles are 
relatively newly established risk factors for cardiovascular disease(30). The ApoB/ApoA1 ratio is a sensitive indicator of cholesterol balance directly related to cardiovascular risk, i.e. the lower the ratio, the lower the risk.

After inclusion of ApoB/ApoA1-ratio in the regression model together with total cholesterol in men the latter became negatively associated with 10-year risk of cardiovascular death. A positive association of low TC levels with risk of death from coronary heart disease has earlier been reported in a Russian cohort study undertaken in 1980s(26). Hence, one may conclude that same forces increasing cardiovascular mortality are still present and influent in the Russian population in our days.

Another sensitive marker of lipid status - LDL/HDL-ratio was also directly associated with the 10-risk of cardiovascular and all-cause death but only in men. This finding was is in line with the results of others(31). The strength of the association was lower than that for ApoB/ApoA1-ratio.

One may question why pattern of association of serum lipids with mortality was so different in men and women. One explanation may lay in an effect-modification by life-style, primarily, alcohol habits. Both ApoB/ApoA1- and LDL/HDL-ratio have in their denominators factors which levels increase with drinking(27-29). To answer these questions, a new large population-based study is needed since ours had limited power. Nutritional status and mortality Levels of serum albumin represent a sensitive indicator of nutritional status and morbidity. In our study lower albumin levels at baseline were associated with higher cardiovascular and all-cause mortality in men and women confirming thereby importance 
of nutritional factors in the mortality epidemic in Russia. The direction and the strength of the association were comparable with those reported in the literature(32;33).

\section{Reference List}

(1) Highlights on health in the Russian Federation 2005. World Health Organisation 2010 [cited 2010 Apr 14];Available from: URL: http://www.euro.who.int/document/E88405.pdf

(2) Table: Birth rates, mortality and natural increase of the population. Federal State Statistics Service of Russia (Goskomstat) 2011 [cited 2011 Feb 3];Available from: URL: $\underline{\text { http://www.gks.ru/free_doc/new_site/population/demo/demo21.xls }}$

(3) The whole population by age and gender [Russian]. The official site of Russian 2002 census 2010 [cited 2010 Apr 19];Available from: URL: http://perepis2002.ru/ct/doc/_02-01_new.xls

(4) Medico-demographic indicators of Arkhangelsk region in 2006 [Russian]. Arkhangelsk, Russia: The Arkhangelsk Regional Healthcare Department; 2007.

(5) Population by gender and one-year age. The 1st of January 1986 - 2010 [Norwegian]. Statistics Norway 2010 [cited 2010 May 11];Available from: URL: http://www.ssb.no/folkemengde/

(6) Zaridze D, Maximovitch D, Lazarev A, Igitov V, Boroda A, Boreham J, et al. Alcohol poisoning is a main determinant of recent mortality trends in Russia: evidence from a detailed analysis of mortality statistics and autopsies. Int J Epidemiol 2009 Feb;38(1):143-53.

(7) Life expectancy at birth (number of years) [Russian]. Federal State Statistics Service of Russia (Goskomstat) 2010 [cited 2010 Apr 12];Available from: URL: http://www.gks.ru/free_doc/new_site/population/demo/demo26.xls 
(8) Stegmayr B, Vinogradova T, Malyutina S, Peltonen M, Nikitin Y, Asplund K. Widening gap of stroke between east and west. Eight-year trends in occurrence and risk factors in Russia and Sweden. Stroke 2000 Jan;31(1):2-8.

(9) Puska P, Matilainen T, Jousilahti P, Korhonen H, Vartiainen E, Pokusajeva S, et al. Cardiovascular risk factors in the Republic of Karelia, Russia, and in North Karelia, Finland. Int J Epidemiol 1993 Dec;22(6):1048-55.

(10) Kuulasmaa K, Tunstall-Pedoe H, Dobson A, Fortmann S, Sans S, Tolonen H, et al. Estimation of contribution of changes in classic risk factors to trends in coronaryevent rates across the WHO MONICA Project populations. Lancet 2000 Feb 26;355(9205):675-87.

(11) Averina M, Nilssen O, Brenn T, Brox J, Kalinin AG, Arkhipovsky VL. High cardiovascular mortality in Russia cannot be explained by the classical risk factors. The Arkhangelsk Study 2000. Eur J Epidemiol 2003;18(9):871-8.

(12) Sidorenkov O, Nilssen O, Grjibovski AM. Metabolic syndrome in Russian adults: associated factors and mortality from cardiovascular diseases and all causes. BMC Public Health 2010 Sep 29;10(1):582.

(13) Leon DA, Shkolnikov VM, McKee M, Kiryanov N, Andreev E. Alcohol increases circulatory disease mortality in Russia: acute and chronic effects or misattribution of cause? Int J Epidemiol 2010 Jun 30.

(14) Leon DA, Saburova L, Tomkins S, Andreev E, Kiryanov N, McKee M, et al. Hazardous alcohol drinking and premature mortality in Russia: a population based case-control study. Lancet 2007 Jun 16;369(9578):2001-9.

(15) Zaridze D, Brennan P, Boreham J, Boroda A, Karpov R, Lazarev A, et al. Alcohol and cause-specific mortality in Russia: a retrospective case-control study of 48,557 adult deaths. Lancet 2009 Jun 27;373(9682):2201-14.

(16) Malyutina S, Bobak M, Simonova G, Gafarov V, Nikitin Y, Marmot M. Education, marital status, and total and cardiovascular mortality in Novosibirsk, Russia: a prospective cohort study. Ann Epidemiol 2004 Apr;14(4):244-9.

(17) Dennis BH, Zhukovsky GS, Shestov DB, Davis CE, Deev AD, Kim H, et al. The association of education with coronary heart disease mortality in the USSR Lipid Research Clinics Study. Int J Epidemiol 1993 Jun;22(3):420-7.

(18) Perlman F, Bobak M. Socioeconomic and behavioral determinants of mortality in posttransition Russia: a prospective population study. Ann Epidemiol 2008 Feb;18(2):92-100.

(19) Koivumaa-Honkanen H, Honkanen R, Viinamaki H, Heikkila K, Kaprio J, Koskenvuo M. Self-reported life satisfaction and 20-year mortality in healthy Finnish adults. Am J Epidemiol 2000 Nov 15;152(10):983-91. 
(20) Sidorenkov O, Nilssen O, Brenn T, Martiushov S, Arkhipovsky VL, Grjibovski AM. Prevalence of the metabolic syndrome and its components in Northwest Russia: the Arkhangelsk study. BMC Public Health 2010;10:23.

(21) Perova NV, Oganov RG, Williams DH, Irving SH, Abernathy JR, Deev AD, et al. Association of high-density-lipoprotein cholesterol with mortality and other risk factors for major chronic noncommunicable diseases in samples of US and Russian men. Ann Epidemiol 1995 May;5(3):179-85.

(22) Malyutina S, Bobak M, Kurilovitch S, Gafarov V, Simonova G, Nikitin Y, et al. Relation between heavy and binge drinking and all-cause and cardiovascular mortality in Novosibirsk, Russia: a prospective cohort study. Lancet 2002 Nov 9;360(9344):1448-54.

(23) Migration of population in the Arkhangelsk region in 1998-2009 [Russian]. Arkhangelsk Regional Center of the Federal State Statistics Service (Arkhangelskstat) 2010 [cited 2010 Dec 19];Available from: URL: http://www.arhangelskstat.ru/digital/DocLib7/\%D0\%9C\%D0\%B8\%D0\%B3\%D1 \%80\%D0\%B0\%D1\%86\%D0\%B8\%D1\%8F\%20\%D0\%BD\%D0\%B0\%D1\%81\% D0\%B5\%D0\%BB\%D0\%B5\%D0\%BD\%D0\%B8\%D1\%8F/\%D0\%9C\%D0\%B8\% D0\%B3\%D1\%80\%D0\%BD\%D0\%B0\%D1\%811.htm

(24) Davis CE, Deev AD, Shestov DB, Perova NV, Plavinskaya SI, Abolafia JM, et al. Correlates of mortality in Russian and US women. The Lipid Research Clinics Program. Am J Epidemiol 1994 Feb 15;139(4):369-79.

(25) Stevens J, Evenson KR, Thomas O, Cai J, Thomas R. Associations of fitness and fatness with mortality in Russian and American men in the lipids research clinics study. Int J Obes Relat Metab Disord 2004 Nov;28(11):1463-70.

(26) Shestov DB, Deev AD, Klimov AN, Davis CE, Tyroler HA. Increased risk of coronary heart disease death in men with low total and low-density lipoprotein cholesterol in the Russian Lipid Research Clinics Prevalence Follow-up Study. Circulation 1993 Sep;88(3):846-53.

(27) Averina M, Nilssen O, Brenn T, Brox J, Arkhipovsky VL, Kalinin AG. Factors behind the increase in cardiovascular mortality in Russia: apolipoprotein AI and B distribution in the Arkhangelsk study 2000. Clin Chem 2004 Feb;50(2):346-54.

(28) De Oliveira E Silva ER, Foster D, McGee HM, Seidman CE, Smith JD, Breslow JL, et al. Alcohol consumption raises HDL cholesterol levels by increasing the transport rate of apolipoproteins A-I and A-II. Circulation 2000 Nov 7;102(19):2347-52.

(29) Rimm EB, Williams P, Fosher K, Criqui M, Stampfer MJ. Moderate alcohol intake and lower risk of coronary heart disease: meta-analysis of effects on lipids and haemostatic factors. BMJ 1999 Dec 11;319(7224):1523-8. 
(30) Walldius G, Jungner I. The apoB/apoA-I ratio: a strong, new risk factor for cardiovascular disease and a target for lipid-lowering therapy--a review of the evidence. J Intern Med 2006 May;259(5):493-519.

(31) Lewington S, Whitlock G, Clarke R, Sherliker P, Emberson J, Halsey J, et al. Blood cholesterol and vascular mortality by age, sex, and blood pressure: a metaanalysis of individual data from 61 prospective studies with 55,000 vascular deaths. Lancet 2007 Dec 1;370(9602):1829-39.

(32) Danesh J, Collins R, Appleby P, Peto R. Association of fibrinogen, C-reactive protein, albumin, or leukocyte count with coronary heart disease: meta-analyses of prospective studies. JAMA 1998 May 13;279(18):1477-82.

(33) Goldwasser P, Feldman J. Association of serum albumin and mortality risk. J Clin Epidemiol 1997 Jun;50(6):693-703. 
Table 1 Baseline characteristics of men and women in the study cohort

\begin{tabular}{|c|c|c|c|}
\hline \multirow[t]{2}{*}{ Factors } & Men & Women & \multirow[t]{2}{*}{$\mathbf{P}^{1}$} \\
\hline & \multicolumn{2}{|c|}{ Number,\% Number,\% } & \\
\hline \multicolumn{3}{|l|}{ Age, years } & $<0.001$ \\
\hline $18-29$ & $524(26.7)$ & $375(21.6)$ & \\
\hline $30-39$ & 357 (18.2) & 317 (18.2) & \\
\hline $40-49$ & 447 (22.7) & $420(24.2)$ & \\
\hline $50-59$ & 308 (15.7) & 305 (17.5) & \\
\hline $60+$ & 330 (16.7) & $321(18.4)$ & \\
\hline \multicolumn{3}{|l|}{ Marital status } & $<0.001$ \\
\hline Single & 655 (33.3) & $807(46.4)$ & \\
\hline Married & 1311 (66.7) & 931 (53.6) & \\
\hline \multicolumn{3}{|l|}{ Education } & $<0.001$ \\
\hline Secondary school & 443 (22.5) & $452(26.0)$ & \\
\hline College & $1201(61.1)$ & $834(48.0)$ & \\
\hline University & 322 (16.4) & $452(26.0)$ & \\
\hline Current smoking & $1114(56.7)$ & $370(21.3)$ & $<0.001$ \\
\hline Sedentary lifestyle & $452(23.0)$ & $695(40.0)$ & $<0.001$ \\
\hline \multicolumn{3}{|c|}{ Frequency of alcohol intake } & $<0.001$ \\
\hline Abstainers & $240(12.2)$ & $471(27.1)$ & \\
\hline Once a month or less & $442(22.5)$ & $580(33.4)$ & \\
\hline 2-4 times a month & $1001(50.9)$ & $599(34.5)$ & \\
\hline$\geq 5$ times a month & $283(14.4)$ & $88(5.1)$ & \\
\hline \multicolumn{3}{|c|}{ Number of $\mathbf{A U}^{2}$ on one occasion } & $<0.001$ \\
\hline Abstainers & $236(12.0)$ & $469(27.0)$ & \\
\hline 1-4 AU & $792(40.3)$ & $1009(58.1)$ & \\
\hline$\geq 5 \mathrm{AU}$ & $938(47.7)$ & $260(15.0)$ & \\
\hline \multicolumn{3}{|c|}{ Take $\geq 80 \mathrm{~g}$ alcohol on occasion } & $<0.001$ \\
\hline Never & $594(30.2)$ & 1163(66.9) & \\
\hline Less than once/month & $467(23.8)$ & $355(20.4)$ & \\
\hline$\geq 1$ times a month & $905(46.0)$ & $220(12.7)$ & \\
\hline AUDIT score, mean (SD) & $6.63(5.19)$ & $2.88(3.47)$ & $<0.001$ \\
\hline CAGE score, mean (SD) & $0.67(0.99)$ & $0.31(0.68)$ & $<0.001$ \\
\hline Depression & $210(10.7)$ & $586(33.7)$ & $<0.001$ \\
\hline Sleeping problems & $221(11.2)$ & $606(34.9)$ & $<0.001$ \\
\hline Quality of life & $5.78(1.76)$ & $5.28(1.84)$ & $<0.001$ \\
\hline \multicolumn{3}{|l|}{ BMI } & $<0.001$ \\
\hline$<25$ & $974(49.5)$ & $799(46.0)$ & \\
\hline $25-29.9$ & 725 (36.9) & $544(31.3)$ & \\
\hline$\geq 30$ & $267(13.6)$ & 395 (22.7) & \\
\hline DBP $\geq 90$ mmHg, \% & $315(16.0)$ & 249 (14.3) & 0.16 \\
\hline Self-reported MI/stroke, $\%$ & $59(3)$ & $53(3)$ & 1.0 \\
\hline HBA1c, \%, mean (SD) ${ }^{3}$ & $4.92(0.53)$ & $4.98(0.61)$ & 0.002 \\
\hline TC, mmol/l, mean (SD) & $4.98(1.18)$ & $5.16(1.24)$ & $<0.001$ \\
\hline HDL-C, mmol/l, mean (SD) & $1.27(0.36)$ & $1.38(0.35)$ & $<0.001$ \\
\hline TG, mmol/l, mean (SD) & $1.38(0.91)$ & $1.28(0.76)$ & $<0.001$ \\
\hline LDL/HDL ratio & $2.62(1.17)$ & $2.52(1.25)$ & 0.007 \\
\hline ApoB/ApoA ratio & $0.68(0.21)$ & $0.62(0.21)$ & $<0.001$ \\
\hline GGT, U/L, mean (SD) & $43.8(60.6)$ & $28.3(38.9)$ & $<0.001$ \\
\hline CRP, mg/l, mean (SD) & $3.20(9.04)$ & $2.72(5.8)$ & 0.06 \\
\hline Albumin, g/l, mean (SD) & $44.2(3.0)$ & $42.4(2.95)$ & $<0.001$ \\
\hline Total & 1966 & 1738 & \\
\hline
\end{tabular}

${ }^{1}$ Calculated by Pearson's chi-squared test and Independent sample T-test

${ }^{2}$ One Alcohol Unit (AU) is equivalent to 13.8 grams of pure ethanol

${ }^{3}$ HBA1c (glycohemoglobin) was measured in 1919 men and 1640 women 
Table 2 Mortality in the cohort in absolute numbers by cause, gender and age during the 10-year follow-up

\begin{tabular}{lccc}
\hline Cause of death (ICD-10 codes) & $\begin{array}{c}\text { Age, } \\
\text { years }\end{array}$ & $\begin{array}{c}\text { Men } \\
\text { (N) }\end{array}$ & $\begin{array}{c}\text { Women } \\
\text { (N) }\end{array}$ \\
\hline All external causes & $<50$ & 12 & 5 \\
V01-Y98 & $\geq 50$ & 9 & 1 \\
\hline \multicolumn{1}{c}{ Suicides/ homicides } & $<50$ & 2 & 2 \\
$\quad$ X6n-Y3n & $\geq 50$ & 2 & 1 \\
\hline Cardiovascular diseases & $<50$ & 12 & 6 \\
I00-I99 & $\geq 50$ & 65 & 46 \\
\hline Malignancies & $<50$ & 6 & 4 \\
C00-C97 & $\geq 50$ & 28 & 20 \\
\hline Other causes ${ }^{1}$ & $<50$ & 5 & $2(3)$ \\
& $\geq 50$ & $6(10)$ & $7(10)$ \\
\hline Total & All & 147 & 95 \\
\hline
\end{tabular}

${ }^{1}$ In brackets given together with deaths were cause is unknown 
Table 3 Relative Risks of death from cardiovascular diseases by social, life-style, psycho-social stress indicators and other risk factors

\begin{tabular}{|c|c|c|c|c|}
\hline & \multicolumn{2}{|c|}{ Men } & \multicolumn{2}{|c|}{ Women } \\
\hline & Model $1^{1}$ & Model 2 & Model $1^{1}$ & Model 2 \\
\hline Married (yes vs. no) & $0.90(0.54-1.50)$ & $0.75(0.44-1.29)$ & $0.53(0.26-1.11)$ & $0.57(0.27-1.19)$ \\
\hline \multicolumn{5}{|l|}{ Education } \\
\hline Secondary school & Reference & Reference & Reference & Reference \\
\hline College & $1.07(0.64-1.79)$ & $1.23(0.72-2.08)$ & $1.03(0.52-2.04)$ & $1.19(0.57-2.50)$ \\
\hline University & $0.75(0.37-1.52)$ & $0.78(0.38-1.61)$ & $1.01(0.41-2.51)$ & $1.34(0.53-3.39)$ \\
\hline Smoking (yes vs. no) & $0.91(0.57-1.46)$ & $1.03(0.62-1.71)$ & $1.13(0.26-5.01)$ & $0.65(0.14-2.96)$ \\
\hline Low physical activity & $1.29(0.82-2.07)$ & $1.17(0.71-1.92)$ & $1.82(0.88-3.74)$ & $1.65(0.78-3.48)$ \\
\hline \multicolumn{5}{|c|}{ Frequency of alcohol intake ${ }^{3}$} \\
\hline Abstainers & Reference & Reference & Reference & Reference \\
\hline$\leq 1$ times a month & $1.64(0.89-3.03)$ & $2.04(1.09-3.84)^{*}$ & $1.09(0.48-2.50)$ & $1.18(0.52-2.71)$ \\
\hline 2-4 times a month & $1.17(0.61-2.24)$ & $1.45(0.75-2.80)$ & $1.59(0.63-4.02)$ & $1.61(0.64-4.08)$ \\
\hline$\geq 5$ times a month & $0.80(0.26-2.46)$ & $1.06(0.34-3.30)$ & $2.65(0.33-20.96)$ & $3.76(0.42-33.5)$ \\
\hline \multicolumn{5}{|c|}{ Number of AU on one occasion ${ }^{3}$} \\
\hline Abstainers & Reference & Reference & Reference & Reference \\
\hline 1-4 AU & $1.55(0.86-2.82)$ & $1.92(1.04-3.55)^{*}$ & $1.07(0.50-2.30)$ & $1.12(0.52-2.41)$ \\
\hline$\geq 5 \mathrm{AU}$ & $1.07(0.55-2.09)$ & $1.33(0.67-2.63)$ & $2.90(1.01-8.35)^{*}$ & $3.21(1.07-9.58) *$ \\
\hline \multicolumn{5}{|c|}{ Take $\geq 80 \mathrm{~g}$ alcohol on occasion } \\
\hline Never & Reference & Reference & Reference & Reference \\
\hline Less than once/month & $0.91(0.49-1.70)$ & $1.10(0.58-2.08)$ & $2.67(0.96-7.39)$ & $3.33(1.16-9.59) *$ \\
\hline$\geq 1$ times a month & $0.85(0.48-1.50)$ & $0.96(0.53-1.75)$ & $4.17(1.35-12.9) \S$ & $5.06(1.54-16.7) \S$ \\
\hline AUDIT score $^{3}$ & $1.01(0.96-1.06)$ & $1.02(0.98-1.08)$ & $1.20(1.10-1.30) \ddagger$ & $1.26(1.14-1.40) \ddagger$ \\
\hline CAGE score $^{3}$ & $1.21(0.96-1.52)$ & $1.24(0.99-1.54)$ & $2.28(1.36-3.84) \S$ & $2.46(1.44-4.19) \ddagger$ \\
\hline Depression & $0.79(0.42-1.50)$ & $0.70(0.36-1.37)$ & $1.35(0.78-2.34)$ & $1.11(0.62-1.97)$ \\
\hline Sleeping problems & $0.84(0.48-1.47)$ & $0.69(0.37-1.30)$ & $1.08(0.60-1.95)$ & 0.91 (0.49-1.69) \\
\hline Low quality of life & $1.41(0.88-2.26)$ & $1.29(0.78-2.12)$ & $1.90(1.03-3.50)^{*}$ & $1.71(0.87-3.35)$ \\
\hline \multicolumn{5}{|l|}{ BMI } \\
\hline$<25$ & Reference & Reference & Reference & Reference \\
\hline $25-29.9$ & $0.96(0.58-1.59)$ & $0.73(0.44-1.21)$ & $1.02(0.51-2.03)$ & $0.89(0.44-1.80)$ \\
\hline$\geq 30$ & $1.34(0.72-2.51)$ & $0.62(0.30-1.26)$ & $1.40(0.72-2.74)$ & $1.54(0.74-3.21)$ \\
\hline DBP $\geq 90 \mathrm{mmHg}$ & $1.45(0.91-2.32)$ & 1.75 (1.09-2.89)* & 0.67 (0.34-1.30) & $0.63(0.32-1.28)$ \\
\hline Log GGT & $1.51(0.74-3.10)$ & 1.07 (0.50-2.29) & $1.90(0.90-4.01)$ & $1.29(0.58-2.87)$ \\
\hline Log CRP & $1.73(1.14-2.62) \S$ & $1.51(0.94-2.42)$ & $1.27(0.70-2.31)$ & $1.22(0.60-2.48)$ \\
\hline Albumin & $0.93(0.88-0.99) *$ & $0.93(0.88-0.98) *$ & $0.89(0.83-0.95) \ddagger$ & $0.93(0.86-1.01)$ \\
\hline Total cholesterol $^{4}$ & $1.03(0.85-1.25)$ & $0.98(0.81-1.19)$ & $1.05(0.85-1.30)$ & 1.07 (0.86-1.32) \\
\hline HDL-C ${ }^{4}$ & $0.36(0.17-0.75) \S$ & $0.37(0.18-0.77) \S$ & $0.49(0.20-1.16)$ & $0.45(0.17-1.17)$ \\
\hline Triglycerides $^{4}$ & $1.02(0.81-1.29)$ & $0.94(0.73-1.23)$ & 1.31 (0.99-1.91) & $1.25(0.92-1.71)$ \\
\hline $\mathbf{L D L} / \mathbf{H D L}^{4}$ & $1.29(1.11-1.52) \S$ & $1.26(1.06-1.49) \S$ & $1.10(0.92-1.32)$ & $1.16(0.95-1.41)$ \\
\hline АроВ/АроA1 & $8.53(3.79-19.2) \ddagger$ & $7.62(3.15-18.4) \ddagger$ & 3.08 (1.06-8.93)* & $3.12(1.08-8.98) \S$ \\
\hline
\end{tabular}

${ }^{1}$ Model 1 adjusted for age; Model 2 adjusted for age, education, smoking, frequency of taking $\geq 80 \mathrm{~g}$ alcohol on occasion, physical activity, DBP, ApoB/ApoA1 ratio, BMI, history of CVD

${ }^{2} \mathrm{P}$-value corresponding to * $\mathrm{p} \leq 0.05 ; \S \mathrm{p} \leq 0.01 ; \uparrow \mathrm{p} \leq 0.001$

${ }^{3}$ Adjusted for the same covariates as in Model 2, except frequency of taking $\geq 80 \mathrm{~g}$ alcohol on occasion

${ }^{4}$ Adjusted for the same covariates as in Model 2, except ApoB/ApoA1 ratio 
Table 4 Relative Risks of death from all causes by social, life-style, psycho-social stress indicators and other risk factors

\begin{tabular}{|c|c|c|c|c|}
\hline \multirow[t]{2}{*}{ Risk factors } & \multicolumn{2}{|c|}{ Men } & \multicolumn{2}{|c|}{ Women } \\
\hline & 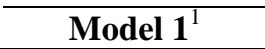 & Model 2 & Model $1^{1}$ & Model 2 \\
\hline Married (yes vs. no) & $1.00(0.69-1.46)$ & $1.02(0.68-1.52)$ & $0.65(0.41-1.04)$ & $0.70(0.44-1.14)$ \\
\hline \multicolumn{5}{|l|}{ Education } \\
\hline Secondary school & Reference & Reference & Reference & Reference \\
\hline College & $0.88(0.61-1.28)$ & $0.97(0.66-1.42)$ & $0.75(0.45-1.26)$ & $0.81(0.47-1.38)$ \\
\hline University & $0.54(0.32-0.92)^{*}$ & $0.58(0.33-1.0)^{*}$ & $0.78(0.42 .1 .44)$ & $0.84(0.45-1.58)$ \\
\hline Smoking (yes vs. no) & $1.25(0.90-1.74)$ & $1.28(0.89-1.83)$ & $0.80(0.31-2.06)$ & $0.62(0.23-1.63)$ \\
\hline Low physical activity & $1.22(0.86-1.72)$ & $1.13(0.79-1.62)$ & $1.32(0.84-2.11)$ & $1.27(0.79-2.05)$ \\
\hline \multicolumn{5}{|c|}{ Frequency of alcohol intake $^{3}$} \\
\hline Abstainers & Reference & Reference & Reference & Reference \\
\hline$\leq 1$ times a month & $1.30(0.81-2.08)$ & $1.56(0.96-2.54)$ & $0.79(0.44-1.41)$ & $0.82(0.46-1.47)$ \\
\hline 2-4 times a month & $1.14(0.71-1.82)$ & $1.44(0.89-2.34)$ & $1.07(0.56-2.06)$ & $1.10(0.57-2.18)$ \\
\hline$\geq 5$ times a month & $0.98(0.49-1.97)$ & $1.18(0.57-2.45)$ & $1.33(0.31-5.80)$ & $1.51(0.33-6.78)$ \\
\hline \multicolumn{5}{|c|}{ Number of AU on one occasion ${ }^{3}$} \\
\hline Abstainers & Reference & Reference & Reference & Reference \\
\hline $1-4 \mathrm{AU}$ & $1.23(0.78-1.94)$ & $1.53(0.96-2.45)$ & $0.84(0.49-1.42)$ & $0.86(0.50-1.46)$ \\
\hline$\geq 5 \mathrm{AU}$ & $1.12(0.70-1.78)$ & $1.35(0.83-2.22)$ & $1.28(0.56-2.93)$ & $1.35(0.59-3.12)$ \\
\hline \multicolumn{5}{|c|}{ Take $\geq 80 \mathrm{~g}$ alcohol on occasion } \\
\hline Never & Reference & Reference & Reference & Reference \\
\hline Less than once/month & $0.84(0.53 .1 .33)$ & $0.93(0.58-1.49)$ & $1.58(0.80-3.15)$ & $1.66(0.83-3.35)$ \\
\hline$\geq 1$ times a month & $1.02(0.69-1.51)$ & $1.05(0.70-1.57)$ & $1.31(0.51-3.40)$ & $1.37(0.52-3.60)$ \\
\hline AUDIT score $^{3}$ & $1.02(0.99-1.06)$ & $1.03(0.99-1.06)$ & $1.06(0.98-1.15)$ & $1.08(0.98-1.18)$ \\
\hline CAGE score ${ }^{3}$ & $1.14(0.97-1.34)$ & $1.16(0.99-1.36)$ & $1.39(0.92-2.10)$ & $1.42(0.94-2.16)$ \\
\hline Depression & $0.87(0.54-1.38)$ & $0.77(0.48-1.25)$ & $1.14(0.76-1.72)$ & $1.01(0.66-1.54)$ \\
\hline Sleeping problems & $1.00(0.67-1.51)$ & $0.86(0.55-1.35)$ & $1.07(0.69-1.64)$ & $0.95(0.61-1.48)$ \\
\hline Low quality of life & $1.28(0.90-1.82)$ & $1.17(0.81-1.70)$ & $1.46(0.95-2.25)$ & $1.29(0.82-2.04)$ \\
\hline \multicolumn{5}{|l|}{ BMI } \\
\hline$<25$ & Reference & Reference & Reference & Reference \\
\hline $25-29.9$ & $0.89(0.63-1.26)$ & $0.78(0.54-1.12)$ & $0.81(0.50-1.31)$ & $0.76(0.46-1.24)$ \\
\hline$\geq 30$ & $0.85(0.52-1.40)$ & $0.56(0.32-0.96)^{*}$ & $0.96(0.59-1.57)$ & $1.01(0.59-1.73)$ \\
\hline $\mathrm{DBP} \geq 90 \mathrm{mmHg}$ & $1.47(1.04-2.08)^{*}$ & $1.75(1.23-2.49) \S$ & $0.87(0.55-1.39)$ & $0.83(0.51-1.35)$ \\
\hline Log GGT & $1.59(0.95-2.51)$ & $1.23(0.72-2.09)$ & 2.03 (1.13-3.67)* & $1.67(0.92-3.04)$ \\
\hline Log CRP & $1.54(1.12-2.10) \S$ & $1.40(1.0-1.97)^{*}$ & $1.38(0.89-2.15)$ & $1.57(0.96-2.57)$ \\
\hline Albumin & $0.95(0.91-1.0)$ & $0.94(0.90-0.99)^{*}$ & $0.90(0.85-0.94)$ & $0.91(0.86-0.96) \ddagger$ \\
\hline Total cholesterol & $1.02(0.89-1.18)$ & $1.02(0.88-1.17)$ & $0.93(0.79-1.10)$ & $0.96(0.82-1.13)$ \\
\hline HDL-C ${ }^{4}$ & $0.64(0.40-1.04)$ & $0.58(0.35-0.95)^{*}$ & 0.54 (0.29-1.01)* & $0.52(0.27-1.00)^{*}$ \\
\hline Triglycerides $^{4}$ & $1.02(0.86-1.20)$ & $1.02(0.85-1.22)$ & $1.12(0.89-1.41)$ & $1.11(0.87-1.42)$ \\
\hline LDL/HDL ${ }^{4}$ & $1.16(1.02-1.31)^{*}$ & $1.18(1.03-1.34)^{*}$ & $1.05(0.91-1.21)$ & $1.09(0.94-1.26)$ \\
\hline АроВ/АроА1 & $4.17(2.17-8.0) \ddagger$ & $4.39(2.22-8.68) \ddagger$ & $1.52(0.63-3.66)$ & $1.98(0.81-4.80)$ \\
\hline
\end{tabular}


Table 5 Distribution of 27 forensic autopsy cases were positive BAC or alcohol surrogates were identified by gender and diagnosis

\begin{tabular}{llcc}
\hline \multicolumn{1}{c}{$\begin{array}{c}\text { Cause of } \\
\text { death }\end{array}$} & \multicolumn{1}{c}{ Alcohol status } & \multicolumn{2}{c}{ Gender } \\
\cline { 2 - 4 } & & Men & Women \\
\hline CVD & Nr autopsies & 29 & 7 \\
V01-Y98 & $\mathrm{N}(\%)$ with alcohol & $10(34.5)$ & $4(57.1)$ \\
\hline External causes & Nr autopsies & 19 & 6 \\
I00-I99 & $\mathrm{N}(\%)$ with alcohol & $7(36.8)$ & $2(33.3)$ \\
\hline Cancer & Nr autopsies & 6 & 6 \\
C00-C97 & $\mathrm{N}(\%)$ with alcohol & $0(0)$ & $0(0)$ \\
\hline Other diseases & Nr autopsies & 5 & 1 \\
& $\mathrm{~N}(\%)$ with alcohol & $4(80)$ & $0(0)$ \\
\hline All deaths & Nr autopsies & 59 & 20 \\
& $\mathrm{~N}(\%)$ with alcohol & $21(35.6)$ & $6(30.0)$ \\
\hline
\end{tabular}

